\title{
Modelling Stock Indexes Volatility of Emerging Markets
}

\author{
Farhan Ahmed ${ }^{1}$ \\ Samia Muhammed Umer ${ }^{2}$ \\ Raza $\mathrm{Ali}^{3}$
}

\begin{abstract}
This study aims to investigate the use of ARCH (autoregressive conditional heteroscedasticity) family models for forecasting volatility of four regional emerging stock markets i.e. KSE 100, BSE-SENSEX, DSE 20 and SSE Composite index. The ARCH, GARCH, EGARCH, TGARCH and PARCH models are used and the best model is selected on the basis of the Akaike information criterion (AIC) and Schwartz information criterion (SIC) over the sample period covering from January 1996 to December 2015. Empirical evidence suggested on the basis of AIC, TGARCH outperformed other models in case of BSE SENSEX, DSE 20 and SSE COMPOSITE index. TGARCH model is considered as the best closely followed by PARCH model, whereas PARCH is also considered as the best performing model for BSE SENSEX, KSE 100 and SSE COMPOSITE index. Meanwhile, on the basis of SIC, GARCH is the best performing model for BSE SENSEX and SSE COMPOSITE, whereas PARCH and EGARCH for KSE 100 and DSE 20 respectively. This study will help portfolio managers, investors and policy makers to make their investment strategies in these emerging markets accordingly.
\end{abstract}

Keywords: Volatility, Forecasting, Emerging Markets

JEL Code: $C 22$

\section{INTRODUCTION}

Stock market plays an important role in any countries economy. Lately stock market forecasting (or prediction) is one of the hottest research topics because of its commercial applications owing to the high stakes and the kinds of lucrative benefits that it offers (Majhi et al., 2007). In addition, it is considered as a challenging job of financial time-series forecast and one of the most important issues in finance. The stock market however, has been investigated by numerous researches, is fundamentally non-linear, nonparametric, and dynamic rather complicated environment (Tan et al., 2005). Miao et al. (2007) and Wang (2002) presented that stock market's movements and fluctuations are affected by several factors like firms' policies, political events, general economic conditions, bank rate, commodity price index, bank exchange rate, investors' expectations, institutional investors' preferences, movements of stock market, psychology and behavior of investors, etc. The understanding and the explanation adequate of the returns of stock markets volatility establishes a fundamental to the study of finance. Investigating data generating process in stock returns, modern research has argued that the factors affecting the asset pricing behavior of investors are explained by non-parametric relationships with expected returns. The predicate of returns of stock markets have showed a significant nonlinearity encouraged from an asymmetric process (Nam et al., 2002; Nam \& Kim, 2003). Forecasting and prediction of stock market returns in today's volatile markets have become a challenging task and represent a major task for traditional time-series estima-

1- Department of Management Sciences, SZABIST Karachi Email: farhan.ahmed@szabist.edu.pk

2- CFA Institute, USA

3- Department of Management Sciences, SZABIST Larkana

\begin{tabular}{llll}
\hline JISR-MSSE & Volume 2 & Number 15 & JulyDec 2017 \\
\hline
\end{tabular}


tion. Therefore, predicting economics and finance movements is reasonably difficult. In the literature there are a various methods applied to explain the behavior of time series and to accomplish this challenge.

In determining forecasting procedures time series plays an important in understanding the underlying structure of variables in economics. Many time series occurring specially in the engineering and natural sciences cannot be modeled through linear processes. These time series have specific trends that are captured and modeled by non-linear processes. The modeling structure for non-linear process is rather complicated as compared to linear time series. Some of the important non-linear series include bilinear, exponential auto regressive, threshold autoregressive, autoregressive conditional heteroscedastic (ARCH), generalized autoregressive heteroscedastic $(\mathrm{GARCH})$ and random and stochastic coefficient models.

The main objective of this paper is to use the ARCH family models to estimate and forecast volatility of the stock market returns of Pakistan, India, Bangladesh and China. These four countries are the leading countries in Asia region. The data set for Pakistan is based on the daily closing stock price from the KSE 100 index, the Indian data set is from the BSE SENSEX index the data set for Bangladesh is drawn from the DSE 100 index and the Chinese data is drawn from SSE COMPOSITE index. Moreover, among different appropriate candidate models, the best models will be selected on the basis of the Akaike information criterion (AIC) as proposed by Akaike (1974), the Schwarz information criterion (SIC) given by Schwarz (1978). The other objective of this paper is to compare the results and choose the precise method to forecast volatility for these three stock market return series.

This paper is organized in different sections, in first section introduction and objectives of the study are discussed. In second and third sections detailed review of literature and research methodology are discussed respectively. In fourth section, empirical analysis and in fifth section conclusion and future research directions are given.

\section{LITERATURE REVIEW}

Over the last two decades volatility in the financial markets gained massive attention and it can be described as the measurement of the variation in the stock price over the time and it is treated as the measurement of risk. French, Schwert and Stambauch (1987) explain the relationship between volatility and stock returns and found the evidence that risk premium is directly related with volatility. However, to directly get volatility is very hard. Busse (1999) witnessed that timing of volatility is an important factor in the returns of mutual funds that has led to higher risk-adjusted returns. Brandt and Jones (2006) argued that financial stock's volatility is predictable and time-varying but estimating the future volatility level is very complex because it is very difficult to find estimators that truly represent the parameters of volatility. Engle (1982) formulated a model known as ARCH model with the variation of conditional variance.

In $\mathrm{ARCH}$ model the restricted variance is dependent upon the previous squared error terms of different lags, even at higher lag, one can hold the maximum number of the restricted variance but a higher order indicates the model is comprised of several parameters which makes the estimation work lengthy, difficult and hard to intercept. Later, in 1986 Bollerslev presented the $\mathrm{GARCH}$ model to overcome the higher order $\mathrm{ARCH}$ problem. The conditional variance is 
dependent upon the previous squared errors and restricted variances of the GARCH model. The extension of ARCH through GARCH is very much similar to the extension of the AR to ARMA model. Engle (2001) shared that GARCH $(1,1)$ is the most easiest and robust model amongst entire volatility family models. Floros (2008) explained volatility and risk in financial markets using daily observation from Israel (TAS-100) index and Egypt (CMA General Index) using GARCH and its variants. Egyptian CMA index was characterized as the most volatile series. Akgiray (1989), Brooks (1996) and Pagan, Schwert (1989) presented that the GARCH models completely fits on the US stocks appropriately. There are several other GARCH extensions like EGARCH (Exponential GARCH) which was proposed by Nelson (1991). Brandt and Jones (2006) used EGARCH model to estimate and predict volatility of S\&P 500.

Engle and Bollerslev (1986) suggested Integrated GARCH (IGARCH) model. Ganger, Ding and Engle (1993) for the first time proposed Power GARCH (PGARCH) model. Lucy and Tully (2006) performed PGARCH models on global gold prices to predict its volatility. Glosten, Runkle and Jaganath (1993) and Zakoian (1994) further proposed Threshold GARCH (TGARCH) model. Chiang (2001) used TGARCH model on seven Asian stock markets to measure the relationship between volatility and returns on stocks. Lastly, Engle and Nag (1993) suggested the Quadratic GARCH (QGARCH) model. Rafique and Kashif-ur-Rehman (2011) applied ARCH, GARCH $(1,1)$ and EGARCH $(1,1)$ on KSE 100 index to study the clustering volatility, excess kurtosis and fat tails of the time series of Karachi stock exchange. They noted that GARCH $(1,1)$ fully captured the volatility persistence. By modeling EGARCH $(1,1)$ "leverage effect" was successfully overcome in KSE 100 index. Magnus and Fosu (2006) predicted the volatility by taking a single index and using the models like RW, GARCH $(1,1)$, EGARCH $(1,1)$ and TGARCH $(1,1)$ on Ghana stock exchange (GSE). Ng and McAleer (2004) performed volatility models like $\operatorname{GARCH}(1,1)$ and TARCH $(1,1)$ on Nikkei 225 index and S\&P 500 Composite index to estimate and forecast the volatility of daily returns. The results suggested that estimation performance of these models were dependent on the data that was used. GARCH $(1,1)$ seemed to perform better with Nikkei 225 index whereas; TGARCH $(1,1)$ was a better measure for S\&P 500 index.

Dikko et.al (2015) studied volatility of insurance stocks listed on the Nigerian stock exchange using five asymmetric and seven asymmetric models. Out of the ten stocks that were studied, eight of them showed ARCH effect. Furthermore, ARCH (1) model was considered as the best fit on the basis of MAE, RMSE and MAPE. The novelty of the research is, no such research study has been conducted at preliminary level to just identify the best fit model for these four regional emergeing stock markets on the basis of too proven criteria: Akaike and Schwartz information criterion. Data and research methodology is covered in next section of the study.

\section{RESEARCH METHODOLOGY}

In this research time series data is used of four Asian emerging stock exchanges i.e. Karachi stock exchange 100 index, Bombay stock exchange SENSEX index, Dhaka stock exchange 20 index and Shanghai stock exchange COMPOSITE index. The study covers a sample period of 20 years starting from January 1, 1996 till December 31, 2015 covering almost 5200 trading days. Each data set includes 4844 observation. The test of normality is conducted for all the transformed series. For this purpose, the Jarque-Bera (JB) test (Jarque and Bera, 1987) of normality is used. The JB test statistic is given below,

\begin{tabular}{llll|l}
\hline JISR-MSSE & Volume 2 & Number 15 & JulyDec 2017 & 21 \\
\hline
\end{tabular}




$$
J B=T\left[\frac{S^{2}}{6}+\frac{(K-3)^{2}}{24}\right]
$$

Where $\mathrm{T}$ is the total number of observations, $\mathrm{S}$ is the coefficient of skewness and $\mathrm{K}$ is the coefficient of kurtosis. To detect the stationarity of time series data that the time series is stable around its mean, two most widely used unit root tests are used (1) Augmented Dickey Fuller (1987), perhaps the most used test (2) Phillip-Perron (1988) test it makes a non-parametric correction to the t-test statistic. The test is robust with respect to unspecified autocorrelation and Heteroscedasticity in the disturbance process of the test equation. In order to confirm whether the time series is stationary the ADF and PP test statistic should be less than its critical value. Following the autoregressive conditional heteroskedasticity $(\mathrm{ARCH})$ model by Engle (1982), there are many extensions of ARCH model, such as GARCH, EGARCH and TGARCH and PARCH known as ARCH family models.

\section{ARCH (Auto Regressive Conditional Heteroscedasticity)}

In 1982 Engle proposed this model, stating that conditional variance of the error/residuals from fitted model at any point in time s dependent on the squared innovations from the past. It is non-linear model which does not take in account that the variances of the error terms are constant and it also elaborates how the variance of the error terms changes. Providing motivation for ARCH family models for time series of financial assets is known as 'volatility clustering' or 'volatility pooling'. Volatility clustering explains the ability of large movements in returns (of any sign) to follow changes and small changes (of any sign) to continue the same trend.

$$
\begin{aligned}
& h_{t}=\omega+\sum_{j=1}^{q} \alpha_{i} \varepsilon_{t-1}^{2} \\
& \varepsilon_{t}=y_{t}-x_{t}{ }^{\prime} b
\end{aligned}
$$

Whereas $q$ is the order of the moving average ARCH terms and $\omega$ and $\alpha i$ are unknown parameters.

\section{GARCH (Generalized Auto Regressive Conditional Heteroscedasticity)}

This model is an extension of ARCH model, proposed by Bollerslev (1986). It suggests that conditional variance of the residual terms also depends on the previous innovations but it is also dependent on the past conditional variances as well. To use GARCH model it is suggested to run it on high frequency data such as daily returns of stock indexes, at lower frequencies the model will not be much effective. If shorter period data is used the result and estimates will not be robust. The primary test before actually forecasting conditional volatility is running Engle's $\mathrm{ARCH}$ test. The equation is given by,

$$
\sigma_{t}^{2}=\alpha_{0}+\sum_{i=1}^{2} \alpha_{i} \varepsilon_{i-i}^{2}+\sum_{j=1}^{n} \beta_{j} \sigma_{i-1}^{2}
$$

Where $\alpha 0>0$, and $\alpha \mathrm{i} 0(\mathrm{i}=1,2, \ldots, \mathrm{q})$, and $\beta \mathrm{j} 0(\mathrm{j}=1,2, \ldots, \mathrm{p})$ are the known parameters. 


\section{EGARCH (Exponential Generalized Auto Regressive Conditional Heteroscedasticity)}

Model EGARCH) model is developed by Nelson (1991). He considered the natural log of conditional variance as linear in some functions of time and past function $\mathrm{Zt}$ to ensure the conditional variance of time series data yt remains positive. The conditional variance equation can be presented in the following form:

$\ln \left(h_{t}\right)=\omega+\sum_{i=1}^{q} \alpha_{i}\left|\frac{\varepsilon_{t-i}}{\sqrt{h_{t-i}}}\right|+\sum_{j=1}^{p} \beta_{j} \ln \left(h_{t-j}\right)+\gamma\left|\frac{\varepsilon_{t-i}}{\sqrt{h_{t-i}}}\right|$

Where, $p \geq 0 ; q>0 ; \omega>0, \alpha i>0, i=1,2,3 \ldots q$ and $\beta j \geq 0, j=1,2,3 \ldots q$.

\section{TGARCH (Threshold Generalized Auto Regressive Conditional Heteroscedasticity)}

Zakoïan (1994) \& Glosten et al. (1993) use the TARCH model with an intention of independence than for the asymmetric effect of the "news" (Brooks, 2008). Form of this model is as follows:

$\ln \sigma_{t}^{2}=\omega+\beta \ln \sigma_{t-1}^{2}+\gamma \frac{u_{t-1}}{\sqrt{\sigma_{t-1}^{2}}}+\alpha\left[\frac{\left|u_{t-1}\right|}{\sqrt{\sigma_{t-1}^{2}}}-\sqrt{\frac{2}{\pi}}\right]$

Where, $\alpha \mathrm{i} \geq 0$ for $\mathrm{i}=1,2,3 \ldots \ldots \mathrm{q}$, and $\gamma \geq 0$ for $\mathrm{j}=1,2,3 \ldots \ldots$.

\section{PARCH (POWER AUTO REGRESSIVE CONDITIONAL HETEROSCEDASTICIY)}

The PARCH model is an extension of the GARCH model with an additional term added to account for possible asymmetries (Brooks, 2008). The conditional variance is now given by asymmetries (Brooks, 2008). The conditional variance is now given by,

$\sigma_{t}^{2}=\alpha_{0}+\alpha_{1} u_{t-1}^{2}+\beta \sigma_{t-1}^{2}+\gamma u_{t-1}^{2} I_{t-1}$

Where, $\alpha i \geq 0$ for $i=1,2,3 \ldots \ldots q$, and $\gamma \geq 0$ for $j=1,2,3 \ldots \ldots . p$.

\section{MODEL SELECTION CRITERION}

Residual analyses are carried out for the diagnostic purposes of the models. Among different appropriate candidate models, the best models are selected on the basis of the Akaike information criterion (AIC) as proposed by Akaike (1974) and the Schwarz information criterion (SIC) given by Schwarz (1978).

$A I C=-2 l T+2 k T$.

$S I C=-2 l T+k \log T / T$.

Where, $\mathrm{k}$ is the number of unknown parameters, $\mathrm{T}$ is the size of the series and 1 is the value of the log likelihood function. 


\section{EMPIRICAL ANALYSIS}

Since all four of the time series are non-stationary, it first needs to be converted into stationary time series data. In table 1, it can observed that two out of four stock indexes i.e. DSE 20 and KSE 100 shows leptokurtic behavior and all stock indexes have positive skewness indicating data has long right tail. The p-value of Jarque Bera is less than its critical value of 5\% signifying the time series data is non-normal as evident from JB value itself.

Table 1: Descriptive Statistics

\begin{tabular}{lllllllll}
\hline Variable & Min & Max & Mean & SD & Kurtosis & Skewness & JB Value & P-value \\
\hline BSE SENSEX & 2600 & 29681 & 10784 & 7499 & 2.11 & 0.589 & 438 & 0.000 \\
DSE 20 & 516.4 & 6092 & 2081 & 964.7 & 4.837 & 1.261 & 1965 & 0.000 \\
KSE 100 & 765.7 & 36228 & 9674 & 9199.9 & 3.854 & 1.27 & 1449.9 & 0.000 \\
SSE COMPOSITE & 2600 & 29681 & 11359 & 7798 & 2.029 & 0.532 & 418.9 & 0.000 \\
\hline
\end{tabular}

This table shows the descriptive statistics of all series undertaken in the study.

As per table 2, unit root test was conducted at both the order of integration. Both ADF and PP failed to reject the null hypothesis at zero level of integration indicating that the series have a unit root problem. To address this issue the series are first differenced and at first level of integration both the tests rejected the null hypothesis concluding that the time series is now stationary and possesses a random walk behavior as evident from the table above that p-value is less than $5 \%$ of critical value.

Table 2: Unit Root Test

\begin{tabular}{lcccl}
\hline Variables & Order of Integration & ADF Test & PP Test & Hypothesis \\
\hline BSE SENSEX & $\mathrm{I}(0)$ & 0.98 & 0.99 & Null hypothesis is not rejected. \\
& $\mathrm{I}(1)$ & 0.00 & 0.00 & Null hypothesis is rejected. \\
\hline DSE 20 & $\mathrm{I}(0)$ & 0.36 & 0.42 & Null hypothesis is not rejected. \\
& $\mathrm{I}(1)$ & 0.00 & 0.00 & Null hypothesis is rejected. \\
\hline KSE 100 & $\mathrm{I}(0)$ & 0.99 & 0.99 & Null hypothesis is not rejected. \\
& $\mathrm{I}(1)$ & 0.00 & 0.00 & Null hypothesis is rejected. \\
\hline SSE & $\mathrm{I}(0)$ & 0.94 & 0.95 & Null hypothesis is not rejected. \\
COMPOSITE & $\mathrm{I}(1)$ & 0.00 & 0.00 & Null hypothesis is rejected. \\
\hline
\end{tabular}

This table shows random walk behavior among series using Augmented Dickey Fuller and Philip-Perron test.

As per table 2, unit root test was conducted at both the order of integration. Both ADF and PP failed to reject the null hypothesis at zero level of integration indicating that the series have a unit root problem. To address this issue the series are first differenced and at first level of integration both the tests rejected the null hypothesis concluding that the time series is now stationary and possesses a random walk behavior as evident from the table above that $\mathrm{p}$-value is less than $5 \%$ of critical value.

\section{ARCH FAMILY MODELS}

In this section five different model of normal ARCH family are tested on the four emerging stock indexes time series data i.e. ARCH, GARCH, TARCH, EGARCH and PARCH.

4- Empirical estimations/outputs for the ARCH-type models can be provided through email if required by the readers of the study. 


\section{ORDINARY LEAST SQUARES FOR ARCH}

First of all ordinary least square was run on first differenced data on all the four emerging stock indexes to determine whether or not there is ARCH effect in the time series. As per the result of output in figure, $\mathrm{p}$-value is less than the critical value of $5 \%$ ensuring that ARCH effect is present in the data. Therefore, it is concluded that the current volatility of emerging stock indexes is significantly influenced by their past volatility of their data.

\section{ARCH MODEL}

In order to detect Auto Regressive Conditional Heteroscedasticity in all four emerging stock indexes, the p-value of residual (RESID $\left.(-1)^{\wedge} 2\right)$ must be less than $5 \%$.

The output of ARCH model indicated that C (constant) is statistically significant for all four emerging stock indexes both in mean and variance equation because its probability value is less than $5 \%$. Furthermore, according to the variance equation the RESID $(-1)^{\wedge} 2$ is also statistically significant as the probability is less than 5\%, which proves that is ARCH effect. Therefore it can be said that the current volatility is greatly influenced by the past volatility.

Table 1. Autoregressive Conditional Heteroscedasticity

\begin{tabular}{|c|c|c|c|c|c|}
\hline Series & Variable & Coefficient & Std. Error & z-Statistics & Prob. \\
\hline \multirow{6}{*}{$\begin{array}{c}\text { BSE Sensex } \\
\text { Index }\end{array}$} & Mean Equation & & & & \\
\hline & @SQRT(GARCH) & 0.355431 & 0.011435 & 31.08225 & 0.0000 \\
\hline & $\mathrm{C}$ & -42.39465 & 2.617263 & -16.19808 & 0.0000 \\
\hline & Variance Equation & & & & \\
\hline & $\mathrm{C}$ & 13424.66 & 187.8109 & 71.47966 & 0.0000 \\
\hline & $\operatorname{RESID}(-1)^{\wedge} 2$ & 0.864143 & 0.025105 & 34.42086 & 0.0000 \\
\hline \multirow{7}{*}{ DSE 20 Index } & Mean Equation & & & & \\
\hline & @SQRT(GARCH) & 0.113635 & 0.022678 & 5.010725 & 0.0000 \\
\hline & C & -2.713963 & 1.295231 & -2.095349 & 0.0361 \\
\hline & Variance Equation & & & & \\
\hline & $\mathrm{C}$ & 60.60081 & 2.246176 & 26.97955 & 0.0000 \\
\hline & $\operatorname{RESID}(-1)^{\wedge} 2$ & 0.153434 & 0.006901 & 22.23294 & 0.0000 \\
\hline & GARCH(-1) & 0.855279 & 0.004834 & 176.9347 & 0.0000 \\
\hline \multirow{6}{*}{$\begin{array}{l}\text { KSE } 100 \\
\text { Index }\end{array}$} & Mean Equation & & & & \\
\hline & @SQRT(GARCH) & 0.222970 & 0.005604 & 39.78459 & 0.0000 \\
\hline & $\bar{C}$ & -11.63397 & 1.125586 & -10.33592 & 0.0000 \\
\hline & Variance Equation & & & & \\
\hline & C & 5517.100 & 73.86299 & 74.69370 & 0.0000 \\
\hline & $\operatorname{RESID}(-1)^{\wedge} 2$ & 1.296865 & 0.033492 & 38.72165 & 0.0000 \\
\hline \multirow{6}{*}{$\begin{array}{c}\text { SSE } \\
\text { Composite } \\
\text { Index }\end{array}$} & Mean Equation & & & & \\
\hline & @SQRT(GARCH) & 0.363912 & 0.012147 & 29.96010 & 0.0000 \\
\hline & $\mathrm{C}$ & -44.87930 & 2.820336 & -15.91275 & 0.0000 \\
\hline & Variance Equation & & & & \\
\hline & $\mathrm{C}$ & 14472.27 & 208.9610 & 69.25821 & 0.0000 \\
\hline & $\operatorname{RESID}(-1)^{\wedge} 2$ & 0.854573 & 0.024250 & 35.24065 & 0.0000 \\
\hline
\end{tabular}




\section{GARCH MODEL}

To detect Generalized Auto Regressive Conditional Heteroscedasticity in all four emerging stock indexes, the p-value of residual (RESID $\left.(-1)^{\wedge} 2\right)$ must be less than $5 \%$.

The results of GARCH model showed that $\mathrm{C}$ (constant) is statistically significant for all emerging stock indexes both in mean and variance equation except for BSE SENSEX index because its probability value is greater than $5 \%$. Furthermore, according to the variance equation the GARCH (-1) and RESID $(-1)^{\wedge} 2$ is also statistically significant as the probability is less than 5\%, which proves that is GARCH effect. Therefore it can be said that the current volatility is greatly influenced by the past volatility.

\section{TGARCH MODEL}

To detect Generalized Auto Regressive Conditional Heteroscedasticity in all four emerging stock indexes, the p-value of residual must be less than 5\%.

The output of TARCH model indicate that none of the $\mathrm{C}$ (constant) is statistically significant for all emerging stock indexes both in mean and variance equation except for KSE 100 index because its probability value is less than $5 \%$. Furthermore, according to the variance equation the $\operatorname{RESID}(-1)^{\wedge} 2^{*}(\operatorname{RESID}(-1)<0)$ and $\operatorname{GARCH}(-1)$ is also statistically significant as the probability is less than $5 \%$, which proves that is TARCH effect. Therefore it can be said that the current volatility is greatly influenced by the past volatility.

\section{PARCH MODEL}

To detect Power Auto Regressive Conditional Heteroscedasticity in all four emerging stock indexes, the p-value of residual must be less than 5\%. The result of PARCH model indicated that none of the $\mathrm{C}$ (constant) is statistically significant for all emerging stock indexes both in mean and variance equation except for KSE 100 index because its probability value is less than $5 \%$. As per the variance equation $\mathrm{C}(3), \mathrm{C}(4), \mathrm{C}(5)$ and $\mathrm{C}(6)$ are also statistically significant as the probability is less than $5 \%$, which proves that is PARCH effect. Therefore it can be said that the current volatility is greatly influenced by the past volatility.

\section{EGARCH MODEL}

In order to detect Exponential Generalized Auto Regressive Conditional Heteroscedasticity in all four emerging stock indexes, the p-value of residuals must be less than 5\%. The output of EGARCH model suggested that none of the C (constant) is statistically significant for all emerging stock indexes in mean equation except for KSE 100 index because its probability value is less than $5 \%$. As per the variance equation $\mathrm{C}(3), \mathrm{C}(4)$, and $\mathrm{C}(5)$ are also statistically significant as the probability is less than $5 \%$, which proves that is EGARCH effect. Therefore it can be said that the current volatility is greatly influenced by the past volatility and also there exists an asymmetric behavior in the volatility, meaning that negative shocks affects differently than positive shocks. 


\section{BEST FIT MODEL SELECTION}

The best fit model for every time series is selected on the basis of Akaike (1974), and Schwarz (1978) information criterion. The model with the lowest information criterion value is considered as the best performing model for that series as given in table 3 below.

Table 3a: Model Selection Criterion - Akaike Information Criterion

\begin{tabular}{llllll}
\hline Index & ARCH & GARCH & TGARCH & PARCH & EGARCH \\
\hline BSE SENSEX & 12.941 & 12.320 & $\mathbf{1 2 . 3 1 9}$ & $\mathbf{1 2 . 3 1 9}$ & 12.323 \\
DSE 20 & 10.080 & $\mathbf{9 . 5 6 5}$ & $\mathbf{9 . 5 6 5}$ & 9.559 & 9.560 \\
KSE 100 & 12.247 & 11.544 & 11.544 & $\mathbf{1 1 . 4 9 2 7}$ & 11.526 \\
SSE COMPOSITE & 13.014 & $\mathbf{1 2 . 4 0 4}$ & $\mathbf{1 2 . 4 0 4}$ & $\mathbf{1 2 . 4 0 4}$ & 12.406 \\
\hline
\end{tabular}

This table shows selection criteria undertaking Akaike information criterion.

Table 3b: Model Selection Criterion - Schwartz Information Criterion

\begin{tabular}{llllll}
\hline Index & ARCH & GARCH & TGARCH & PARCH & EGARCH \\
\hline BSE SENSEX & 12.946 & $\mathbf{1 2 . 3 2 6}$ & 12.327 & 12.329 & 12.331 \\
DSE 20 & 10.080 & 9.571 & 9.572 & 9.568 & $\mathbf{9 . 5 6 7}$ \\
KSE 100 & 12.252 & 11.550 & 11.552 & $\mathbf{1 1 . 5 0 2}$ & 11.534 \\
SSE COMPOSITE & 13.019 & $\mathbf{1 2 . 4 1 1}$ & 12.412 & 12.413 & 12.414 \\
\hline
\end{tabular}

This table shows selection criteria undertaking Akaike information criterion.

Empirical evidence suggested on the basis of AIC in table 3a, TGARCH outperformed other models in case of BSE SENSEX, DSE 20 and SSE COMPOSITE index. TGARCH model is considered as the best closely followed by PARCH model, whereas PARCH is also considered as the best performing model for BSE SENSEX, KSE 100 and SSE COMPOSITE index. Meanwhile, on the basis of SIC in table 3b, GARCH is the best performing model for BSE SENSEX and SSE COMPOSITE, whereas PARCH and EGARCH for KSE 100 and DSE 20 respectively.

\section{CONCLUSION \& AREA OF FURTHER RESEARCH}

In this particular study, ARCH family models are applied on four regional emerging stock indexes, namely BSE SENSEX index of India, DSE 20 index of Bangladesh, KSE 100 index of Pakistan and SSE COMPOSITE index of China. Five different volatility models were used to for study purpose, these are, ARCH, GARCH, TGARCH, PARCH and EGARCH. The best performing models have been selected on the basis Akaike Information Criterion (AIC) and Schwartz Information Criterion (SIC). The model with the lowest value was considered as the best fit model. The daily time series data were used for the indexes. The data includes 4844 observations. The study covers a sample period of 20 years starting from January 1, 1996 till December 31, 2015 covering almost 5200 trading days. Out of the four emerging stock indexes two of them had excess positive kurtosis i.e. DSE 20 index and KSE 100 index, remaining two indexes had platykurtic behavior. All four mentioned indexes showed long positive tails. Time series data was also not normally distributed and had unit root problem which was catered through first differencing. In order to run $\mathrm{ARCH}$ family models time series must satisfy three conditions. Volatility clustering should be in the series, data should have fatter 
tails and that time series data should be of greater frequency. The outcomes of ARCH model indicate that RESID (-1)2 is statistically significant for all four emerging stock indexes both in mean and variance equation proving that the current volatility is greatly influenced by the past volatility.

The results of GARCH also showed that the variance equation of GARCH (-1) is also statistically significant signifying that the current volatility risk is greatly influenced by the past square residual and also $\operatorname{RESID}(-1)^{\wedge} 2$ is statistically significant for all the stock indexes. Outputs of TARCH model showed that according to the variance equation the $\operatorname{RESID}(-1)^{\wedge} 2 *(\operatorname{RESID}(-1)<0)$ and $\operatorname{GARCH}(-1)$ is also statistically significant therefore it can be said that the current volatility is greatly influenced by the past volatility. Results of PARCH model indicates that the variance equation C(3), C (4), C(5) and C(6) are all statistically, implying that the current volatility is greatly influenced by the past volatility. In addition the outputs of EGARCH indicated the variance equation C (3), C (4), and C (5) is also statistically significant. Therefore it can be said that the current volatility is greatly influenced by the past volatility and also there exists an asymmetric behavior in the volatility, meaning that negative shocks affects differently than positive shocks.

Empirical evidence suggested on the basis of AIC, TGARCH outperformed other models in case of BSE SENSEX, DSE 20 and SSE COMPOSITE index. TGARCH model is considered as the best closely followed by PARCH model, whereas PARCH is also considered as the best performing model for BSE SENSEX, KSE 100 and SSE COMPOSITE index. Meanwhile, on the basis of SIC, GARCH is the best performing model for BSE SENSEX and SSE COMPOSITE, whereas PARCH and EGARCH for KSE 100 and DSE 20 respectively.

As per the findings it is advised to analyst, researchers and investors to bear this in mind that the bad shocks in the economy or the stock market can significantly impact the volatility in the event of an economic crisis. For future research, different alternative time series models to cater volatility like, multivariate time series models and stochastic volatility models can be considered.

Moreover, in this paper daily closing data was used for a period of 20 year to forecast the volatility. According to ZHOU (1996) tick by tick, minute by minute data will be more effective in measuring and forecasting volatility and applying ARCH models or other relevant volatility models. The results of the study help practitioners, investors, portfolio managers and other stakeholders to consider the best fit models while testing and forecasting the stock returns volatility in the undertaken stock markets. 


\section{REFERENCES}

Akgiray, V. (1989). Conditional heteroscedasticity in time series of stock returns: Evidence and forecasts. Journal of Business, 55-80.

Andersen, T. G., Bollerslev, T., Diebold, F. X., \& Labys, P. (2003). Modeling and forecasting realized volatility. Econometrica, 71(2), 579-625.

Bollerslev, T. (1986). Generalized autoregressive conditional heteroskedasticity. Journal of econometrics, 31(3), 307-327.

Brandt, M. W., \& Jones, C. S. (2006). Volatility forecasting with range-based EGARCH models. Journal of Business \& Economic Statistics, 24(4), 470-486.

Brooks, C. (1998). Predicting stock index volatility: can market volume help?. Journal of Forecasting, 17(1), 59-80.

Busse, J. A. (1999). Volatility timing in mutual funds: Evidence from daily returns. The Review of Financial Studies, 12(5), 1009-1041.

Dickey, D. A., \& Fuller, W. A. (1981). Likelihood ratio statistics for autoregressive time series with a unit root. Econometrica: Journal of the Econometric Society, 1057-1072.

Ding, Z., Granger, C. W., \& Engle, R. F. (1993). A long memory property of stock market returns and a new model. Journal of empirical finance, 1(1), 83-106.

Tully, E., \& Lucey, B. M. (2007). A power GARCH examination of the gold market. Research in International Business and Finance, 21(2), 316-325.

Engle, R. (2001). GARCH 101: The use of ARCH/GARCH models in applied econometrics. The Journal of Economic Perspectives, 15(4), 157-168.

Engle, R. F., \& Bollerslev, T. (1986). Modelling the persistence of conditional variances. Econometric reviews, 5(1), 1-50.

Engle, R. F., \& Ng, V. K. (1993). Measuring and testing the impact of news on volatility. The journal of finance, 48(5), 1749-1778.

Engle, R. F. (1982). Autoregressive conditional heteroscedasticity with estimates of the variance of United Kingdom inflation. Econometrica: Journal of the Econometric Society, 987-1007.

Floros, C. (2008). Modelling volatility using GARCH models: evidence from Egypt and Israel. Middle Eastern Finance and Economics, (2), 31-41.

French, K. R., Schwert, G. W., \& Stambaugh, R. F. (1987). Expected stock returns and volatility. Journal of financial Economics, 19(1), 3-29.

Glosten, L. R., Jagannathan, R., \& Runkle, D. E. (1993). On the relation between the expected value and the volatility of the nominal excess return on stocks. The 
journal of finance, 48(5), 1779-1801.

Kim, C. J., Morley, J. C., \& Nelson, C. R. (2004). Is there a positive relationship between stock market volatility and the equity premium? Journal of Money, Credit and banking, 339-360.

Kirchler, M., \& Huber, J. (2007). Fat tails and volatility clustering in experimental asset markets. Journal of Economic Dynamics and Control, 31(6), 1844-1874.

Lee, K. J., Chi, A. Y., Yoo, S., \& Jin, J. J. (2008). Forecasting korean stock price index (kospi) using back propagation neural network model, bayesian chiao's model, and sarima model. Journal of Management Information and Decision Sciences, 11(2), 53.

Nelson, D. B. (1991). Conditional heteroskedasticity in asset returns: A new approach. Econometrica: Journal of the Econometric Society, 347-370.

Ning, C., Xu, D., \& Wirjanto, T. (2010). Modeling asymmetric volatility clusters using copulas and high frequency data (No. 1001).

Pagan, A. R., \& Schwert, G. W . (1990). Alternative models for conditional stock volatility. Journal of econometrics, 45(1), 267-290.

Siegel, J. J., \& Schwartz, J. D. (2006). Long-term returns on the original S\&P 500 companies. Financial Analysts Journal, 62(1), 18-31.

Sokolinskiy, O., \& van Dijk, D. (2011). Forecasting volatility with copula-based time series models (No. 11-125/4). Tinbergen Institute Discussion Paper.

Wilson, A., \& Ghahramani, Z. (2010). Copula processes. In Advances in Neural Information Processing Systems (pp. 2460-2468).

Zakoian, J. M. (1994). Threshold heteroskedastic models. Journal of Economic Dynamics and control, 18(5), 931-955.

Zhou, B. (1996). High-frequency data and volatility in foreign-exchange rates. Journal of Business \& Economic Statistics, 14(1), 45-52. 